\title{
Knowledge spillover-based strategic entrepreneurship
}

\author{
João J. Ferreira ${ }^{1} \cdot$ Vanessa Ratten $^{2} \cdot$ Léo-Paul Dana $^{3}$
}

Published online: 8 October 2016

(C) Springer Science+Business Media New York 2016

\begin{abstract}
Research on knowledge spillovers (KS) has each been the subject of much scholarly attention, but has mostly been considered independently rather than in combination with each other important issue - strategic entrepreneurship (SE). The purpose of this special issue is to integrate these two approaches and to develop theory in addition to empirically investigate the phenomenon inspiring future research on the topic. This paper draws on the knowledge spillover-based strategic entrepreneurship in a multilevel context, examines the logic of the approach, and introduces the special issue by summarizing the papers contributions. Future research suggestions from the papers included in the special journal issue are also discussed and explained.
\end{abstract}

Keywords Entrepreneurship · Knowledge spillovers · Strategic entrepreneurship

\section{Introduction}

Knowledge is a core asset and resource for firms that when inappropriately spilled over can endanger their competitive positions in the marketplace (Perri and Peruffo 2016). Knowledge spillovers (KS) are "unintentional flows of knowledge from one network party to another" (Ko and Liu 2015: 663) and differ from other types of knowledge

João J. Ferreira

jjmf@ubi.pt

Vanessa Ratten

v.ratten@latrobe.edu.au

Léo-Paul Dana

lp.dana@montpellier-bs.com

1 University of Beira Interior \& NECE - Research Unit in Business Sciences, Covilhã, Portugal

2 La Trobe University, Melbourne, Australia

3 Montpellier Business School, Montpellier, France 
transfer as there is no deliberate action to obtain the knowledge as it happens by chance (Audretsch and Keilbach 2007). This means for KS to develop there are no specified agreements but rather it is the result of context. As some knowledge is hard to communication and share it depends on the situation as to whether a firm can capitalize on the KS (Acs et al. 2009). KS are becoming more important to entrepreneurship due to their role in product and process innovations (Lee et al. 2016). In this introduction to the special journal issue we define knowledge spillover-based strategic entrepreneurship (SE) as unintentional knowledge flows that can be used for strategic purposes to network entities other than the creators for innovative, risk taking, proactive and competitive business reasons.

As the research on KS has increased significantly we are proposing in this special journal issue that it needs to focus more on strategic entrepreneurial behavior in order to advance the literature. This will help widen the scope of KS to emphasize how entrepreneurial knowledge is used strategically to enable wiser business decisions. This enables us to contribute to the entrepreneurship and management literature by extending the current view of KS by implementing a strategic base for firm-level actions. By doing so, we improve the way firms utilize KS by emphasizing the strategic benefits particularly for entrepreneurial initiatives.

Prior research has discussed the knowledge spillover theory of entrepreneurship but we develop a framework for knowledge spillover-based SE to encourage more research that looks into planned behavior that can be used for competitiveness in the global marketplace. This enables us to contribute to the literature about KS by exploring the way it can be integrated into a strategic perspective. By doing so, we highlight how KS to be successful need to be strategically used in an entrepreneurial manner.

Before discussing the papers in the special journal issue it is important to highlight the important role knowledge plays in entrepreneurship. Knowledge is the way entrepreneurs evaluate opportunities and recognize whether they can contribute to business growth. Yang et al. (2010) in a seminal paper indicated that knowledge can be retrieved after it has been spilled over and the learning process can involve both the originator and recipient of the knowledge. Therefore, the inadvertent spillover of knowledge to other firms is a risk that needs to be managed in a strategic manner.

$\mathrm{KS}$ can be evaluated in terms of magnitude, scope and speed, which is important to understanding whether they have strategic value to a firm (Perri and Peruffo 2016). In terms of magnitude, some KS may be large meaning trade sensitive information is obtained by others that can be used for their competitive advantage. Other KS may be on a smaller scale and continual in nature meaning the information can be used depending on a firm's strategy. The scope of the KS will differ from details about a specific technology to more complex information relating to the industry. The speed of the KS will affect strategy as time sensitive information is obtained.

The benefit of KS it that firms can be more strategically entrepreneurial with less effort and costs (Lee et al. 2016). There are a variety of ways knowledge is spilled over including workers moving between firms and learning from network associations (Medda and Piga 2007). Knowledge that spills over from its source can be utilized by entrepreneurs (Ghio et al. 2015). Despite the usage of the knowledge spillover theory of entrepreneurship there are still gaps and missing areas (Qian and Acs 2013). Ghio et al. (2015:2) in explaining the emergence of the knowledge spillover theory of entrepreneurship states it as "the creation of a new venture is a response to 
opportunities stemming from knowledge generated and not commercially exploited by incumbent firms or academic research institutions".

KS and SE have been identified as critical to the process of creative destruction and creative construction (Agarwal et al. 2007; Ferreira et al. 2017) through which firms, industries, regions, and economies create and rejuvenate themselves (Fernandes et al. 2013). How firms combine entrepreneurial action that creates new opportunities with strategic action that generates competitive advantage is a fundamental question in the emerging field of SE and management studies (Hitt et al. 2002). The literature that associates KS to SE emphasizes that incumbent organizations are an important source of new entrants, particularly when they underutilize the knowledge they create (Agarwal et al. 2004; Klepper 2007; Fernandes and Ferreira 2013). In identifying the role of KS to organizations, SE is a key mechanism behind the process of creative construction. This is due to there being a symbiotic relationship between individuals and their knowledge environments; and co-creators of knowledge may each be able to appropriate the value (Suseno and Ratten 2007; Ratten 2011; Light and Dana 2013; Ferreira et al. 2016).

The mechanism of KS-SE inspires the process of creative construction, where linkages to extant knowledge translate, through the founders, to firm level capabilities, growth, and competitive advantage (Agarwal et al. 2010). Additionally, the effect of individual, organizational, and environmental factors on the incidence and type of KSSE has not been fully developed at the literature (Perri and Peruffo 2016). KS and SE has each been the theme of much academic attention, but have largely been considered separately rather than in conjunction with each other. This special journal issue seeks to merge traditional and modern perspectives in KS-SE by exploring different levels and how it relates to the management field. At the individual level, there is a need to reconcile KS-SE with the parallel stream of literature that examines KS through employee mobility. At the organizational level, the effect of parent status and capabilities on the KS-SE should be examined. Finally, at the environmental-level, the contingency conditions and technological intensity of the industry and/or region needs more attention.

We are confident that this special journal issue will help increase interest in the knowledge spillover theory of entrepreneurship by proposing it should be studied from a more SE perspective. This will help add to the conversation about KS by encouraging more researchers to focus on the strategic dimensions. To shed light on these issues, we have selected seven papers for this special issue in order to build upon and add to KS and SE literature. These papers are introduced in section 3, after section 2 that sets the KS-SE theoretical background.

\section{Special issue papers}

The articles selected for this special issue convey to various degrees the insights we have previously mentioned. The first paper, written by Dennis Lyth Frederiksen and Alexander Brem, entitled "How do entrepreneurs think they create value? A scientific reflection of Eric Ries' lean startup approach", discusses about how entrepreneurs create and capture value and they investigate the merits and characteristics of the methods detailed by Ries through a comparison with leading theories and empirical evidence found in the scientific literature. 
The second paper entitled "The effect of university and regional knowledge spillovers on firms' performance: an analysis of the Spanish USOs" written by María Jesús Rodríguez-Gulías, David Rodeiro-Pazos and Sara Fernández-López, test the hypothesis that the regional and university contexts may partly determine university spin-off (USO) growth, together with firms' internal resources. By adopting an interactionist approach, they found that firm-specific characteristics are important for explaining USO growth, but that regional context also matters.

The third paper "Asymmetric information as a barrier to knowledge spillovers in expert markets", written by Daniel Feser and Till Proeger, barriers to effective knowledge spillovers for markets in which the product can be characterized as a credence good is investigated. The authors focus on the German market for energy efficiency consultants, as an emerging and subsidized sector in which the service offered has strong credence good properties. They conclude that access to certification schemes should be further restricted to increase market transparency and private networks should be supported to achieve the aim of increasing KS.

The fourth paper, entitled "Strategic entrepreneurship and knowledge spillovers: Spatial and aspatial perspectives" written by Sam Tavassoli, Lars Bengtsson, and Charlie Karlsson, investigates the types of KS and what they imply for various dimensions of SE. The authors argue that spatial KS play a major role in increasing the amount of 'inputs' dimension of SE, whilst the aspatial knowledge plays the major role not only for 'inputs', but also for 'rresource orchestration' dimension.

In the fifth paper, entitled "Uncorking knowledge - purposeful spillovers as a strategic tool for capability enhancement in the cork industry", Soumodip Sarkar analyses the value creative potential of knowledge spillover strategies, in which a selected body of knowledge is purposefully and strategically disclosed to competitors. The cork industry provides the framing, where most firms have limited innovation capabilities in an industry under threat from rival alternative technologies.

The sixth paper, written by Johanna Gast, Arndt Werner and Sascha Kraus and entitled "Antecedents of the small firm effect: The role of knowledge spillover and blocked mobility for employee entrepreneurial intentions" takes a closer look at the knowledge spillover model and the blocked mobility approach, assuming that both, the knowledge spillover as well as the blocked mobility effect matter for the individual's decision to enter entrepreneurship. They test how the likelihood to engage in entrepreneurial activity is related to specific management positions in different firm sizes, taking into account possible knowledge spillover and blocked mobility effects.

Finally, Veland Ramadani, Hyrije Abazi-Alili, Léo-Paul Dana, Gadaf Rexhepi and Sadudin Ibraimi with the paper entitled "The impact of knowledge spillovers and innovation on firm performance: Findings from the Balkans countries" focus on a new approach on investigating KS and innovation activities and how affect firmperformance. The authors argue that innovation activities are endogenously related to firm performance, and that the performance of firms is influenced by $\mathrm{KS}$ and innovation activities among other firm characteristics.

\section{Conclusion and future research directions}

The objective of this special journal issue is to demonstrate the need for further and renewed attention in KS-SE research. We have highlighted some reasons why this 
phenomenon constitutes a natural field of investigation for entrepreneurship and management research. Papers included on this special issue provide a comprehensive illustration of the driving factors to be accounted for when attempting to understand KS-SE relationships, as well as methodological approaches to analyzing the phenomenon along various relevant dimension and levels. Both concepts of KS and SE are intrinsically related, and examining issues at their interface is key to understanding the complexity of this research field. We have presented an incomplete list of research issues, which may require new theoretical perspectives or fresh empirical insights on issues related to KS-SE.

The papers in this special journal issue provide interesting research emphasizing the SE perspective of KS. Most previous research has emphasized the general entrepreneurship role that KS have but we are emphasizing the strategic nature of this behavior. This helps account for both the positive and negative effects of KS from a competitive perspective. Lee et al. (2016) suggest that the size of KS can result from cultural and internationalization factors. This may lead to a direction for new research looking into knowledge spillover-based strategic entrepreneurship. It would be of interest for future studies to investigate in more depth the different strategies utilized by firms to harness the value of KS. This is important to enhancing our understanding about the complexity of the knowledge spillover process and how firms can strategize to obtain more relevant and useful knowledge.

Future research can include the topics of global talent management and knowledge spillover-based SE to see the role human capital plays in investment of competitively relevant business ventures. The role of KS and corporate entrepreneurship or other forms of strategic action needs to be researched more deeply. This means more research can utilize SE when evaluating KS and encourage further study. In addition, this special journal issue helps develop knowledge spillover-based strategic entrepreneurship as a theoretical framework adding to the existing knowledge spillover theory of entrepreneurship. This helps to highlight the legitimacy of taking an interdisciplinary perspective to KS, which makes it possible for further entrepreneurship scholars to assess the strategic reasons for this behavior.

We have helped to fill the gap in the literature about KS and strategy by focusing on global competitiveness. We hope future research will explore further how social enterprises differ in their use of KS to determine the strategies they use to obtain information. In addition, the process of knowledge spillover-based strategic entrepreneurship needs to be contextualized in terms of how it is influenced by regulatory, institutional and political norms. This means research is needed on emerging, transition and developed economies to see the direct and indirect effects of knowledge spilloverbased strategic entrepreneurship. Therefore, entrepreneurship scholars need to be cognizant of advancing the literature on KS by incorporating more strategic approaches.

Some of these research issues are already subject of close examination, though much work remains to be done. How do organizational strategies that differ on the continuum of open versus closed systems of innovation affect spatial KS and SE? Are there differences between the effect of market and nonmarket channels of knowledge transfer on SE? Future research should also more deeply investigate KS-SE in different sectors (professional and technological) where spillovers effects are not likely to behave in the same way. Although they are often knowledge intensive thus suggesting that the 
knowledge that could potentially spill onto local and regional firms is an interesting future research area. Furthermore, this special journal issue suggests that services are less likely to stimulate the expansion of connections and collaborations which implies tighter spillover networks.

Scholars in this area should be alert that advancing this literature by trying to fill these gaps is an intimidating task. It requires taking a wider set of appropriate research methods and accessing very sensitive data regarding how firms manage and spill over knowledge. We expect this special journal issue to be more of an auspicious new foundation rather than the final word in a greatly abundant area of research. In particular, there exists considerable scope for academic work that scrutinizes the underlying cause-and-effect mechanisms, the processes through which KS- SE manifest themselves, and the implications in terms of micro, meso, and macro-level data and methodologies for the complex KS-SE spatial orchestration.

Acknowledgments We thank Salvador Roig, the editor of IEMJ for his support and guidance with respect to this special issue.We are grateful to all anonymous reviewers for their cooperation and useful comments. Without their support, it would not have been possible to produce this special issue.

We thank to the authors who submitted manuscripts and modified and revised them in a timely manner to meet the strict deadlines we imposed.

\section{References}

Acs, Z., Braunerhjelm, P., Audretsch, D. B., \& Carlsson, B. (2009). The knowledge spillover theory of entrepreneurship. Small Business Economics, 32(1), 15-30.

Agarwal, R., Echambadi, R., April, F., \& Sarkar, M. (2004). Knowledge transfer through inheritance: spin-out generation, development and performance. Academy of Management Journal, 47, 501-522.

Agarwal, R., Audretsch, D., \& Sarkar, M. B. (2007). The process of creative construction: knowledge spillovers, entrepreneurship, and economic growth. Strategic Entrepreneurship Journal, 1(3/4), 263-286.

Agarwal, R., Audretsch, D., \& Sarkar, M. B. (2010). Knowledge spillovers and strategic entrepreneurship. Strategic Entrepreneurship Journal, 4, 271-283.

Audretsch, D. B., \& Keilbach, M. (2007). The theory of knowledge spillover entrepreneurship. Journal of Management Studies, 44(7), 1242-1254.

Fernandes, C., \& Ferreira, J. (2013). Knowledge spillovers: cooperation between Universities and KIBS. $R \& D$ in Management, 43(5), 461-472.

Fernandes, C., Ferreira, J., \& Raposo, M. (2013). Drivers to firm innovation and their effects on performance: an international comparison. International Entrepreneurship and Management Journal, 9(4), 557-580.

Ferreira, J., Raposo, M., Fernandes, C., \& Dejardin, M. (Eds.) (2016). Knowledge Intensive business services and regional competitiveness. United Kingdom: Routledge.

Ferreira, J., Dana, L., \& Ratten, V. (2017). Knowledge spillover-based strategic entrepreneurship. United Kingdom: Routledge forthcoming.

Ghio, N., Guerini, M., Lehmann, E., \& Rossi-Lamastra, C. (2015). The emergence of the knowledge spillover theory of entrepreneurship. Small Business Economics, 44, 1-18.

Hitt, M. A., Sexton, D. L., Ireland, R. D., \& Camp, S. M. (2002). Strategic entrepreneurship: integrating entrepreneurial and strategic management perspectives. In M. A. Hitt, D. L. Sexton, R. D. Ireland, \& S. M. Camp (Eds.), Strategic entrepreneurship: creating a new mindset (pp. 1-16). Oxford, U.K.: Blackwell Publishers.

Klepper, S. (2007). Disagreements, spinoffs, and the evolution of Detroit as the capital of the U.S. automobile industry. Management Science, 53(4), 616-631.

Ko, W. W., \& Liu, G. (2015). Understanding the process of knowledge spillovers: the learning to become social enterprises. Strategic Entrepreneurship Journal, 9, 263-285. 
Lee, K., Chen, K., \& Yoon, M. (2016). Comparing the productivity impacts of knowledge spillovers from network and arm's length industries: findings from business groups in Korea. Industrial and Corporate Change, 28(3), 407-427.

Light, I., \& Dana, L. (2013). Boundaries of social capital in entrepreneurship. Entrepreneurship Theory and Practice, 37(3), 603-624.

Medda, G., \& Piga, C. (2007). Technological spillovers and productivity in Italian manufacturing firms. Working Paper: Loughborough University.

Perri, A., \& Peruffo, E. (2016). Knowledge spillovers from FDI: a critical review from the international business perspective. International Journal of Management Reviews, 18, 3-21.

Qian, H., \& Acs, Z. J. (2013). An absorptive capacity theory of knowledge spillover entrepreneurship. Small Business Economics, 40(2), 185-197.

Ratten, V. (2011). Sport-based entrepreneurship: towards a new theory of entrepreneurship and sport management. International Entrepreneurship and Management Journal, 7(1), 57-69.

Suseno, Y., \& Ratten, V. (2007). A theoretical framework of alliance performance: the role of trust, social capital and knowledge development. Journal of Management and Organization, 13(1), 4-23.

Yang, H., Phelps, C., \& Steensma, K. (2010). Learning from what others have learned from you: the effects of knowledge spillover on originating firms. Academy of Management Journal, 54(2), 371-389. 